\title{
Evaluation of genetic risk scores for lipid levels using genome-wide markers in the Framingham Heart Study Stephen R Piccolo ${ }^{1}$, Ryan P Abo ${ }^{1}$, Kristina Allen-Brady ${ }^{1}$, Nicola J Camp ${ }^{1}$, Stacey Knight ${ }^{1}$, Jeffrey L Anderson ${ }^{2,3}$ and Benjamin D Horne*1,2
}

Addresses: ${ }^{1}$ Department of Biomedical Informatics, School of Medicine, University of Utah, 26 South 2000 East, Salt Lake City, Utah 84112 , USA, ${ }^{2}$ Cardiovascular Department, Intermountain Medical Center, 5121 South Cottonwood Street, Salt Lake City, Utah 84107, USA and ${ }^{3}$ Cardiology Division, School of Medicine, University of Utah, 30 North 1900 East, Salt Lake City, Utah 84132, USA

E-mail: Stephen R Piccolo - stephen.piccolo@hsc.utah.edu; Ryan P Abo - ryan.abo@hsc.utah.edu; Kristina Allen-Brady - kristina.allen@hsc.utah.edu; Nicola J Camp - nicola.camp@utah.edu; Stacey Knight - stacey.knight@hsc.utah.edu; Jeffrey L Anderson - jeffrey.anderson@imail.org; Benjamin D Horne* - benjamin.horne@imail.org ${ }^{*}$ Corresponding author

from Genetic Analysis Workshop 16

St Louis, MO, USA 17-20 September 2009

Published: 15 December 2009

BMC Proceedings 2009, 3(Suppl 7):S46 doi: 10.1186/1753-656I-3-S7-S46

This article is available from: http://www.biomedcentral.com/I753-656I/3/S7/S46

(C) 2009 Piccolo et al; licensee BioMed Central Ltd.

This is an open access article distributed under the terms of the Creative Commons Attribution License (http://creativecommons.org/licenses/by/2.0), which permits unrestricted use, distribution, and reproduction in any medium, provided the original work is properly cited.

\begin{abstract}
Background: Multiple single-nucleotide polymorphisms have been associated with low-density lipoprotein cholesterol (LDL-C), high-density lipoprotein cholesterol (HDL-C), and triglyceride (TG) levels. In this paper, we evaluate a weighted and an unweighted approach for estimating the combined effect of multiple markers (using genotypes and haplotypes) on lipid levels for a given individual.

Methods: Using data from the Framingham Heart Study SHARe genome-wide association study, we tested genome-wide genotypes and haplotypes for association with lipid levels and constructed genetic risk scores (GRS) based on multiple markers that were weighted according to their estimated effects on LDL-C, HDL-C, and TG. These scores (GRS-LDL, GRS-HDL, and GRS-TG) were then evaluated for associations with LDL-C, HDL-C, and TG, and compared with results of an unweighted method based on risk-allele counts. For comparability of metrics, GRS variables were divided into quartiles.

Results: GRS-LDL quartiles were associated with LDL-C levels $\left(p=2.1 \times 10^{-24}\right)$, GRS-HDL quartiles with HDL-C $\left(p=5.9 \times 10^{-22}\right)$, and GRS-TG quartiles with TG $\left(p=5.4 \times 10^{-25}\right)$. In comparison, these $p$-values were considerably lower than those for the associations of the unweighted GRS quartiles for LDL-C $\left(p=3.6 \times 10^{-7}\right)$, HDL-C $\left(p=6.4 \times 10^{-16}\right)$, and TG $\left(p=4.1 \times 10^{-10}\right)$.

Conclusion: GRS variables were highly predictive of LDL-C, HDL-C, and TG measurements, especially when weighted based on each marker's individual association with those intermediate risk phenotypes. The allele-count GRS approach that does not weight the GRS by individual marker associations was considerably less predictive of lipid and lipoprotein measures when the same genetic markers were utilized, suggesting that substantially more risk-associated genetic marker information is encapsulated by the weighted GRS variables.
\end{abstract}




\section{Background}

Low-density lipoprotein cholesterol (LDL-C), high-density lipoprotein cholesterol (HDL-C), and triglycerides (TG) are accepted risk predictors for coronary artery disease (CAD) $[1,2]$. Recently published genome-wide association studies reported novel loci for LDL-C, HDL$\mathrm{C}$, and $\mathrm{TG}$, while also confirming several previously described loci [3-5]. Those studies replicate each other for many of the loci; however, it is unclear how the combined effect of these markers for a given patient should be estimated most effectively.

The genetic risk score (GRS) model is an approach for evaluating multiple related markers simultaneously in association testing for clinical phenotypes such as lipid levels. A recent publication reported an unweighted, integer-based GRS calculated as the sum of risk alleles associated with LDL-C and HDL-C [6]. We previously introduced the concept of aggregating polygenic information in a GRS weighted by the estimated effect of each marker on intermediate risk phenotypes [7]. For this investigation, we hypothesized that the weighted GRS approach would be more powerful than an integer-based GRS because it accounts for variability in the effect of each marker on the phenotype and thus may better represent the complex physiology that drives changes in lipid and lipoprotein levels.

Risk scores proposed thus far, including our own, are based on modelling the contributions of multiple, individual single-nucleotide polymorphisms (SNPs). We hypothesized that haplotypes also are relevant for identifying association evidence and that such biologically relevant markers are overlooked in single-marker analyses. Hence, we also performed haplotype-based association testing in regions where individual SNPs were below the threshold for genome-wide significance and included these markers in GRS models.

Using markers that individually were associated with lipid/lipoprotein levels, we constructed weighted and unweighted GRS metrics for individuals in the Framingham Heart Study and estimated the ability of each composite measure to predict lipid levels.

\section{Methods}

\section{GAWI6 data from Framingham Heart Study}

For this analysis, SNP data from the Genetic Analysis Workshop 16 (GAW16) Problem 2 (real phenotype data) were utilized. These data arose from the Framingham Heart Study SHARe genome-wide association study that evaluated DNA markers for a large subset of the Framingham Heart Study participants using the Affymetrix GeneChip ${ }^{\circledR}$ Human Mapping 500 k Array Set. The data were hosted by and acquired through the NIH dbGAP tool. This investigation was in compliance with the Data Use Agreement required for access to this data set as well as with the requirements of the University of Utah's Institutional Review Board.

\section{Clinical data elements}

The Framingham data set contained phenotypes for 373 individuals from the original cohort, 2,760 from the offspring cohort, and 3,997 from the third generation. Data elements for each participant were selected from the first available study exam for which total cholesterol, HDL-C, and TG levels were available. Because LDL-C measurements were not provided, values were estimated for each participant using the equation:

$$
L D L-C=\text { Total Cholesterol }-H D L-C-(0.2 \cdot T G) .
$$

Of the 7,130 participants, 397 were excluded because of missing measurements for cholesterol, HDL-C, or TG at all available study visits.

\section{Association testing}

A genome-wide analysis was undertaken to test association of genotypes and haplotypes with LDL-C, HDL-C, and TG. Before this, an additional 322 individuals were excluded because they reported medication use for the treatment of dyslipidemia. Quality control also screened out SNPs and participants with $<98 \%$ genotyping success and SNPs not in Hardy-Weinberg equilibrium $(p<0.001)$. After filtering these individuals, 6,411 remained for association testing.

Genotypes were tested for association with each phenotype using two randomly assigned (on a per-individual basis) subsets of the study population-one with $n=$ 3,847 participants (60\% of total population) and another with $n=2,564$ participants $(40 \%$ of total population). The purpose of dividing the data was to select markers that could reach significance (though not necessarily at a genome-wide level) in two samples. We performed a quantitative association test using the PLINK software [8] with default configuration settings and a significance level of $p<0.001$. SNPs identified in this step were carried forward for use in the GRS models.

Haplotypes were constructed and tested for association with each phenotype. The PLINK software [8] was used on the full data set to identify SNPs that obtained a $p$-value between $10^{-2}$ and $10^{-4}$. We chose this threshold range with the goal of identifying SNPs that did not reach genome-wide significance alone but that would be substantially more significant as part of a haplotype. The regions containing these SNPs were ranked using a scoring metric that increased according to the 
significance level of nearby SNPs $\left(<10^{-2}=+1,<10^{-3}=+2\right.$, or $\left.<10^{-4}=+3\right)$. After identification of an initial SNP with a $p$-value between $10^{-2}$ and $10^{-4}$, the score for that region was increased until 15 nearby SNPs failed to reach at least a significance level of $10^{-2}$. Haplotype analyses were then pursued in the top ten scoring regions (which spanned 25 kilobases and contained 7 SNP markers). The haplotype analyses were performed using hapConstructor [9], which uses a forward-backward search algorithm to construct haplotypes and test for association. Its haplotype-mining technique starts with single SNPs and builds up haplotypes SNP-by-SNP, searching for the most significant haplotype across multiple models (dominant, recessive, and additive). The SNP sets considered need not be contiguous. It then uses a difference-of-means test statistic to test for haplotype associations and assesses significance via a Monte Carlo approach (500,000 null simulations maximum). The two most significant haplotypes for each phenotype were used in the GRS models. The full data set was used for identifying haplotypes due to the lack of a straightforward approach for combining results from two data subsets.

\section{Weighted GRS}

GRS variables for each phenotype were calculated separately for each participant (in the full data set), including those on anti-dyslipidemia medications. TG levels were natural-log transformed. The estimated effect size for each genotype selected from the association analysis described above was calculated as the mean (median for TG) difference in lipid levels between those with the wild-type variant and those homozygote for the rare variant (effect $=0$ for heterozygotes). For each marker, wild-type, heterozygote, and homozygote recessive genotype carriers received a score of $-1,0$, or -1 , respectively, multiplied by the marker's estimated effect size. These scores were summed into a GRS for each participant.

Due to the approximately continuous distribution of the weighted GRS values, these variables were divided into quartiles of similar sample size for the purposes of comparing association statistics with those computed for the unweighted GRS variable and to present the data in a clinically relevant framework in which thresholds are used for decision-making. Linear mixed models [10] were used to test for association of GRS variables with LDL-C, HDL-C, and TG, with family membership included in each model as a random-effects variable to adjust for pedigree membership. Multivariate analysis of variance was also used to simultaneously model the association of GRS-LDL, GRS-HDL, and GRS-TG with the dependent variables LDL-C, HDL-C, and TG to compute coefficients of determination that were comparable to the unweighted GRS.

\section{Unweighted GRS}

The unweighted, risk-allele based GRS method [6] is calculated for each participant as the sum of risk allele counts across each marker that predicts LDL-C, HDL-C, or TG. This unweighted GRS was composed using the same markers as the weighted analysis and was evaluated on the same data set of participants. Any marker associated with multiple lipid/lipoprotein phenotypes was included only once in the summation. A value of 0 , 1 , or 2 was assigned to each SNP based on carriage of the same number of copies of the risk allele. These values were then summed for each participant and divided into quartiles for comparative purposes. Association of this GRS with LDL-C, HDL-C, and TG was performed as above using a linear mixed model and coefficients of determination calculated using multivariate analysis of variance.

\section{Results}

\section{Marker selection}

For LDL-C, six SNPs reached $p<0.001$ in both data subsets (Table 1). SNPs associated with HDL-C at $p<0.001$ in both subsets included 11 SNPs on chromosome 8p21 that defined two haplotypes in the region $3^{\prime}$ to the $L P L$ gene. A single SNP in each of these haplotypes was sufficient to explain $>90 \%$ of the haplotypic variance, and thus represented the haplotype in the GRS. Nine SNPs had $p<0.001$ in both subsets for TG. Of these SNPs, rs599839 had the strongest individual association with any phenotype (LDL-C), obtaining a $p$-value of $9.5 \times 10^{-13}$ in the first data subset and $2.2 \times 10^{-16}$ in the entire data set.

For all three phenotypes, a number of regions existed where haplotype associations were an order of magnitude more significant than any single SNP in the region. For HDL-C, seven haplotypes achieved $p<10^{-4}$, and one haplotype attained a $p$-value of $8.0 \times 10^{-6}$. For LDL-C, two haplotypes reached $p<10^{-4}$. For TG, two haplotypes reached $p \leq 6.0 \times 10^{-4}$. For the latter two phenotypes, no haplotype attained a $p$-value less than $10^{-5}$. The results for the top two haplotypes associated with each phenotype are listed in Table 2.

\section{GRS association}

Table 3 shows the results of testing for association between the weighted GRS and lipid/lipoprotein levels. The GRS for each phenotype was associated far more strongly than the association that was observed for the phenotype with any individual marker (compare with Table 1). Some weak cross-association was seen for 
Table I: SNPs associated with LDL-C, HDL-C, and TG in GWAS, with the gene that they are in or near

\begin{tabular}{|c|c|c|c|c|c|c|}
\hline \multirow[b]{2}{*}{ Gene } & \multirow[b]{2}{*}{ SNP } & \multirow[b]{2}{*}{ Chr } & \multicolumn{3}{|c|}{$p$-Value } & \multirow[b]{2}{*}{ Effect size $(\mathrm{mg} / \mathrm{dL})^{a}$} \\
\hline & & & Subset I & Subset 2 & Overall & \\
\hline \multicolumn{7}{|l|}{ LDL-C } \\
\hline $\mathrm{PSRCI}^{\mathrm{b}}$ & rs599839 & $|p| 3$ & $9.5 \times 10^{-13}$ & $1.6 \times 10^{-6}$ & $2.2 \times 10^{-16}$ & -16.7 \\
\hline CELSR2 ${ }^{\mathrm{b}}$ & rs 4970834 & $|p| 3$ & $5.6 \times 10^{-7}$ & $6.8 \times 10^{-5}$ & $1.1 \times 10^{-9}$ & -10.3 \\
\hline PSMA5 & rs 17586966 & $|p| 3$ & $1.8 \times 10^{-5}$ & $3.6 \times 10^{-4}$ & $2.8 \times 10^{-7}$ & -8.8 \\
\hline MTPN & rs 1365360 & $7 q 33$ & $4.2 \times 10^{-4}$ & $7.8 \times 10^{-4}$ & $1.4 \times 10^{-6}$ & 7.7 \\
\hline $\mathrm{DCDCl} / 5$ & rsI58584 & $|\mathrm{Ip}| 4$ & $2.7 \times 10^{-4}$ & $5.3 \times 10^{-4}$ & $2.3 \times 10^{-7}$ & 7.1 \\
\hline RORA & rs782918 & $15 q 22$ & $3.2 \times 10^{-4}$ & $6.3 \times 10^{-4}$ & $3.1 \times 10^{-7}$ & -9.8 \\
\hline \multicolumn{7}{|l|}{ HDL-C } \\
\hline $\mathrm{LPL}^{\mathrm{c}}$ & rsl7482753 & $8 p 21$ & $5.4 \times 10^{-10}$ & $9.2 \times 10^{-6}$ & $5.5 \times 10^{-13}$ & II.I \\
\hline LPL & rs 10503669 & $8 p 21$ & $1.1 \times 10^{-9}$ & $4.9 \times 10^{-6}$ & $2.5 \times 10^{-13}$ & 12.4 \\
\hline LPL & rs 17410962 & $8 p 21$ & $7.4 \times 10^{-8}$ & $2.9 \times 10^{-5}$ & $6.9 \times 10^{-11}$ & 8.5 \\
\hline LPL & rs 17489268 & $8 p 21$ & $1.1 \times 10^{-9}$ & $3.5 \times 10^{-6}$ & $6.6 \times 10^{-15}$ & 4.5 \\
\hline LPL & rs 17411024 & $8 p 21$ & $4.6 \times 10^{-8}$ & $1.5 \times 10^{-5}$ & $1.6 \times 10^{-11}$ & 5.5 \\
\hline LPL & rs $174 \mid 1031$ & $8 p 21$ & $2.1 \times 10^{-9}$ & $3.2 \times 10^{-6}$ & $1.3 \times 10^{-14}$ & 4.5 \\
\hline LPL & rs 17411126 & $8 p 21$ & $3.3 \times 10^{-9}$ & $7.7 \times 10^{-6}$ & $6.1 \times 10^{-14}$ & 4.4 \\
\hline LPL & rs765547 & $8 p 21$ & $4.3 \times 10^{-9}$ & $6.1 \times 10^{-6}$ & $4.6 \times 10^{-14}$ & 4.5 \\
\hline LPL & rsII986942 & $8 p 21$ & $1.1 \times 10^{-6}$ & $4.0 \times 10^{-4}$ & $3.1 \times 10^{-9}$ & 3.6 \\
\hline LPL & rs|837842 & $8 p 21$ & $4.9 \times 10^{-9}$ & $1.8 \times 10^{-6}$ & $1.7 \times 10^{-14}$ & 4.6 \\
\hline LPL & rs1919484 & $8 p 21$ & $5.9 \times 10^{-9}$ & $2.7 \times 10^{-6}$ & $3.2 \times 10^{-14}$ & 4.6 \\
\hline CETP ${ }^{c}$ & rs9989419 & $16 q 13$ & $1.1 \times 10^{-4}$ & $4.6 \times 10^{-4}$ & $8.2 \times 10^{-7}$ & -3.6 \\
\hline LIPG $^{b}$ & rs7240405 & $|8 q 2|$ & $1.0 \times 10^{-4}$ & $6.9 \times 10^{-4}$ & $5.3 \times 10^{-7}$ & -3.6 \\
\hline LIPG & rs4939883 & $|8 q 2|$ & $2.9 \times 10^{-5}$ & $6.2 \times 10^{-4}$ & $1.7 \times 10^{-7}$ & -3.6 \\
\hline$A C A A 2^{b}$ & rs6507945 & $|8 q 2|$ & $4.6 \times 10^{-4}$ & $1.0 \times 10^{-4}$ & $6.8 \times 10^{-7}$ & -3 \\
\hline \multicolumn{7}{|l|}{ Triglycerides } \\
\hline SUMFI & rs317608 & $3 p 26$ & $5.7 \times 10^{-4}$ & $1.4 \times 10^{-4}$ & $4.0 \times 10^{-7}$ & 26 \\
\hline RASGEFIB & rs4382026 & $4 q 21$ & $6.3 \times 10^{-4}$ & $3.6 \times 10^{-5}$ & $5.3 \times 10^{-9}$ & 22 \\
\hline BAZIB & rs2074755 & $7 q 11$ & $1.4 \times 10^{-5}$ & $2.0 \times 10^{-4}$ & $3.9 \times 10^{-10}$ & -13 \\
\hline $\mathrm{LPL}^{\mathrm{c}}$ & rs 17489268 & $8 p 21$ & $1.5 \times 10^{-6}$ & $1.6 \times 10^{-4}$ & $9.8 \times 10^{-12}$ & -13 \\
\hline LPL & rs $174|103|$ & $8 p 21$ & $9.3 \times 10^{-7}$ & $1.6 \times 10^{-4}$ & $6.0 \times 10^{-12}$ & -13 \\
\hline LPL & rs 174|| $\mid 26$ & $8 p 21$ & $1.4 \times 10^{-6}$ & $2.0 \times 10^{-4}$ & $1.3 \times 10^{-11}$ & -13 \\
\hline LPL & rs765547 & $8 p 21$ & $3.6 \times 10^{-6}$ & $4.9 \times 10^{-4}$ & $6.9 \times 10^{-11}$ & -13 \\
\hline LPL & rs|837842 & $8 p 21$ & $4.8 \times 10^{-6}$ & $3.4 \times 10^{-4}$ & $7.1 \times 10^{-11}$ & -13 \\
\hline LPL & rs1919484 & $8 p 21$ & $1.7 \times 10^{-5}$ & $3.3 \times 10^{-4}$ & $3.6 \times 10^{-10}$ & -12 \\
\hline
\end{tabular}

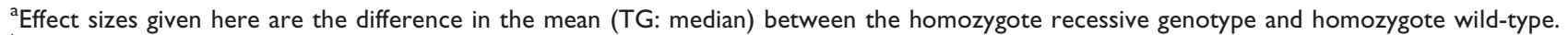
bee Kathiresan et al. [5].

'See Purcell et al. [8].

Table 2: The two most significant haplotypes ${ }^{a}$ for each phenotype

\begin{tabular}{|c|c|c|c|c|c|c|}
\hline Phenotype & Chr & SNPs & Haplotype & Model & $p$-Value & Effect size $^{b}$ \\
\hline HDL-C & 5 & rs922556, rs10070979 & $1-2$ & Dominant & $8.0 \times 10^{-6}$ & $-16.1 \mathrm{mg} / \mathrm{dL}$ \\
\hline HDL-C & 3 & rs272472I, rs384828 & $2-2$ & Dominant & $5.1 \times 10^{-4}$ & $-1.9 \mathrm{mg} / \mathrm{dL}$ \\
\hline LDL-C & 6 & rs316024, rs576075, rs6|4564, rs533452 & $2-1-1-1$ & Dominant & $5.3 \times 10^{-5}$ & $3.4 \mathrm{mg} / \mathrm{dL}$ \\
\hline LDL-C & 7 & rs4947934, rs4947936 & $2-1$ & Additive & $6.0 \times 10^{-5}$ & $16.4 \mathrm{mg} / \mathrm{dL}$ \\
\hline TG & 3 & rs7645357, rs4685635 & $2-2$ & Additive & $5.0 \times 10^{-4}$ & $-9.0 \mathrm{mg} / \mathrm{dL}$ \\
\hline TG & 10 & rs603269, rs475945 & $2-2$ & Additive & $6.0 \times 10^{-4}$ & $3.0 \mathrm{mg} / \mathrm{dL}$ \\
\hline
\end{tabular}

${ }^{\text {a SNPs with }} p<10^{-2}$ and $p>10^{-4}$ were used to construct haplotypes and associations were tested in hapConstructor [9].

bean (TG: median) difference for listed haplotype vs. most common haplotype.

GRS-LDL with HDL-C and TG, for GRS-HDL with TG, and for GRS-TG with HDL-C.

Table 4 shows the association results for the unweighted GRS. It is of note that the association with LDL-C would not have achieved genome-wide significance if it had been a single marker. The lower predictive ability of the unweighted GRS is understandable given the integerbased composition and the lower range of 6-20. (See Table 4. Compare this with the range of values for GRSLDL, GRS-HDL, and GRS-TG in Table 3).

Coefficients of determination for the unweighted GRS were $r^{2}=0.007,0.016$, and 0.010 for LDL-C, HDL-C, and 
Table 3: Weighted GRS results and GRS associations with lipid/lipoprotein levels ${ }^{\mathrm{a}}$

\begin{tabular}{|c|c|c|c|c|c|c|c|c|c|}
\hline \multirow[b]{2}{*}{ GRS } & \multirow[b]{2}{*}{ Min } & \multirow[b]{2}{*}{ Max } & \multirow[b]{2}{*}{ Mean } & \multirow[b]{2}{*}{ S.D. } & \multicolumn{4}{|c|}{ Mean (LDL-C \& HDL-C)/median (TG) in GRS by quartile } & \multirow[b]{2}{*}{$p$-Value } \\
\hline & & & & & $\mathbf{I}$ & 2 & 3 & 4 & \\
\hline GRS-LDL & -34.8 & 15 & -2.69 & 6.8 & & & & & \\
\hline LDL-C & & & & & 107.2 & 115.8 & II8.I & 122.2 & $2.1 \times 10^{-24}$ \\
\hline HDL-C & & & & & 53.9 & 53.5 & 52.3 & 53.0 & 0.07 \\
\hline TG & & & & & 81.0 & 83.0 & 83.0 & 81.0 & 0.04 \\
\hline GRS-HDL & -10.2 & 17 & -1.28 & 3.5 & & & & & \\
\hline LDL-C & & & & & 116.1 & 116.3 & 117.2 & II5.I & 0.6 \\
\hline HDL-C & & & & & 50.5 & 51.7 & 54.3 & 56.2 & $5.9 \times 10^{-22}$ \\
\hline TG & & & & & 83.0 & 87.0 & 84.0 & 76.0 & $3.4 \times 10^{-6}$ \\
\hline GRS-TG & -26.0 & 31 & -2.10 & 8 & & & & & \\
\hline LDL-C & & & & & 115.1 & 116.6 & 117.4 & 115.5 & 0.43 \\
\hline HDL-C & & & & & 54.9 & 54.1 & 51.5 & 52.5 & $7.7 \times 10^{-9}$ \\
\hline TG & & & & & 72.0 & 79.0 & 86.0 & 94.0 & $5.4 \times 10^{-25}$ \\
\hline
\end{tabular}

${ }^{a}$ Results of association testing using a linear mixed model with family membership included in the model as a random-effects variable. Phenotype values are in $\mathrm{mg} / \mathrm{dL}$.

Table 4: Unweighted GRS (sum of risk alleles carried, as defined in literature reports [6]) and its association with lipid/lipoprotein levels ${ }^{a}$

\begin{tabular}{|c|c|c|c|c|c|c|c|c|c|}
\hline \multirow[b]{2}{*}{ GRS } & \multicolumn{4}{|c|}{ Number of risk alleles carried } & \multicolumn{4}{|c|}{ Mean (LDL-C \& HDL-C)/median (TG) in GRS by quartile } & \multirow[b]{2}{*}{$p$-Value } \\
\hline & Min & Max & Mean & S.D. & $\mathbf{I}$ & 2 & 3 & 4 & \\
\hline & 6 & 20 & 12.8 & 2.1 & & & & & \\
\hline LDL-C & & & & & 112.8 & 113.4 & 117.9 & 119.9 & $3.6 \times 10^{-7}$ \\
\hline HDL-C & & & & & 56.2 & 53.8 & 51.8 & 51.2 & $6.4 \times 10^{-16}$ \\
\hline TG & & & & & 75.0 & 84.0 & 84.0 & 87.0 & $4.1 \times 10^{-10}$ \\
\hline
\end{tabular}

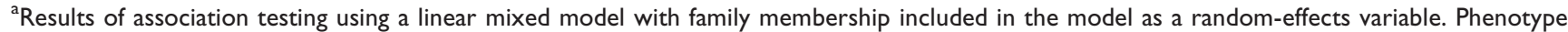
values are in $\mathrm{mg} / \mathrm{dL}$.

TG, respectively. In comparison, modelling of GRS-LDL, GRS-HDL, and GRS-TG showed $r^{2}=0.025,0.023$, and 0.024 for LDL-C, HDL-C, and TG. Although low (but not much lower than a recent report using 30 SNPs [11] that showed $\left.r^{2}=0.06-0.09\right), r^{2}$ was greater for the weighted GRS approach.

GRS associations using the weighted GRS methods and including the two best haplotype markers for LDL-C, HDL$\mathrm{C}$, and TG provided marked improvement (Table 5) in the association of GRS-LDL with LDL-C $\left(p=6.0 \times 10^{-28}\right)$ and GRS-HDL with HDL-C $\left(p=6.2 \times 10^{-25}\right)$, but not for GRSTG with TG $\left(p=6.7 \times 10^{-23}\right.$, which is lower than the GRS that did not use haplotype markers [see Table 3]). Changes in associations due to inclusion of haplotype markers were on the order of $10^{-4}$ for GRS-LDL with LDL-C, $10^{-3}$ for GRS-HDL with HDL-C, and $10^{1}$ for GRS-TG with TG.

\section{Discussion}

Many SNPs influence lipid and lipoprotein levels [12]. This study of GRS models illustrates the potential to stratify genetic risk for complex phenotypes by accounting for polygenic effects. Aggregating data from many markers into a single GRS variable allows genetic and biological information related to a phenotype to be condensed into a statistical metric of low dimensionality.

We identified multiple SNPs that were associated $(p<0.001)$ with lipid levels in two data subsets. Most of these attained genome-wide statistical significance in the full data set, even after a conservative Bonferroni correction. The weighted GRS variables were associated with the phenotypes at a substantially better significance level (lower $p$-value), supporting the concept that a score based on multiple SNPs may be used effectively to represent the joint contributions of components in the underlying biological pathway.

In this study, the associations with LDL-C, HDL-C, and TG were greater for the weighted GRS than for the unweighted GRS, a single composite metric based only on risk-allele carriage. GRS metrics that use only the carriage of risk alleles may account only for the presence and not the relative value of those alleles [6,13]. While shown here and previously $[6,13]$ to have some value, in an unweighted GRS the relative contribution of individual genetic markers is ignored, thus treating each as equal in effect and potentially mis-specifying the actual risk relationship. Based on these results, our weighted 
Table 5: Weighted GRS composed from both SNP and haplotype markers ${ }^{\mathrm{a}}$

\begin{tabular}{|c|c|c|c|c|c|c|c|c|c|}
\hline \multirow[b]{2}{*}{ GRS } & \multirow[b]{2}{*}{ Min } & \multirow[b]{2}{*}{ Max } & \multirow[b]{2}{*}{ Mean } & \multirow[b]{2}{*}{ S.D. } & \multicolumn{4}{|c|}{ Mean (LDL-C \& HDL-C)/median (TG) in GRS by quartiles } & \multirow[b]{2}{*}{ p-Value } \\
\hline & & & & & I & 2 & 3 & 4 & \\
\hline GRS-LDL & -34.8 & 21 & -1.59 & 7.3 & & & & & \\
\hline LDL-C & & & & & 107.7 & 115.2 & 119.1 & 122.7 & $6.0 \times 10^{-28}$ \\
\hline HDL-C & & & & & 54.3 & 53.5 & 53.2 & 53.2 & 0.22 \\
\hline TG & & & & & 79.0 & 81.0 & 83.0 & 79.0 & 0.055 \\
\hline GRS-HDL & -27.0 & 17 & -1.74 & 3.6 & & & & & \\
\hline LDL-C & & & & & 115.7 & 116.4 & 117.2 & 115.5 & 0.53 \\
\hline HDL-C & & & & & 50.5 & 51.7 & 54.9 & 56.9 & $6.2 \times 10^{-25}$ \\
\hline TG & & & & & 84.0 & 84.5 & 83.0 & 75.0 & $5.6 \times 10^{-8}$ \\
\hline GRS-TG & -32.0 & 31 & -2.59 & 8.4 & & & & & \\
\hline LDL-C & & & & & 114.5 & 118.2 & 116.8 & 116.2 & 0.07 \\
\hline HDL-C & & & & & 55.0 & 53.5 & 52.5 & 52.6 & $4.5 \times 10^{-5}$ \\
\hline $\mathrm{TG}$ & & & & & 72.0 & 81.0 & 85.0 & 90.0 & $6.7 \times 10^{-23}$ \\
\hline
\end{tabular}

${ }^{\text {a}}$ Results of association testing using a linear mixed model with family membership included in the model as a random-effects variable. Phenotype values are in $\mathrm{mg} / \mathrm{dL}$.

method appears to provide an additional ability to extract clinically meaningful genetic information for a risk pathway and encapsulate it into a useful, lowdimension variable.

In this study, each weighted GRS showed strong association with its target phenotype. Though they likely would not supplant the need for standard serum measurements of lipid and lipoprotein levels, these GRSs potentially could be useful in identifying individuals early in life who are at increased lifetime risk, which can lead to advanced phenotypes such as CAD $[1,2]$. Clinicians potentially could also use the GRS information to better target medical therapies and diagnostic screening for preventive purposes. This analysis also suggests that a GRS approach may be more useful and effective at characterizing risk of coronary heart disease endpoints than individual genetic markers, although this remains to be tested.

This study has several limitations. The GRS models were evaluated on the same data set on which association testing and construction of the models were performed. This likely led to over-fitting of the models, potentially biasing significance levels for the GRS association testing. However, both the weighted and unweighted GRS models would be affected by this bias and thus the comparisons between them should remain valid.

Further, the genome-wide association analyses using PLINK were done using a naïve approach that did not account for the family structure in the Framingham Heart Study data. In a study based on these data, some of the authors report in another GAW16 paper [14] that even though a naïve approach is anti-conservative, the results from an empirical analysis would have been highly correlated with the results of this naïve approach.

\section{Conclusion}

GRS variables aggregating genetic and intermediate risk phenotype information were highly predictive of LDL-C, HDL-C, and TG measurements, and these associations were improved with inclusion of haplotype information at loci for which SNPs had only weak associations. Summation of risk alleles in an integer-based unweighted GRS were substantially less predictive of the lipid/lipoprotein phenotypes.

\section{List of abbreviations used}

CAD: Coronary artery disease; GAW16: Genetic Workshop Analysis Workshop 16; GRS: Genetic risk scores; HDL-C: High-density lipoprotein cholesterol; LDL-C: Low-density lipoprotein cholesterol; SNP: Single-nucleotide polymorphisms; TG: Triglyceride.

\section{Competing interests}

The authors declare that they have no competing interests.

\section{Authors' contributions}

SRP and RPA participated in processing data, conceiving the study design, and writing the manuscript. KA-B participated in processing data, conceiving the study design, and critically revising the manuscript. NJC participated in conceiving the study design and critically revising the manuscript. SK participated in performing statistical analysis and critically revising the manuscript. JLA participated in critically revising the manuscript. BDH participated in conceiving the study design, performing statistical analysis, and writing the manuscript. All authors read and approved the final manuscript.

\section{Acknowledgements}

SRP, RPA and SK were supported by National Library of Medicine training grant TI5 LM007/24. NJC was supported by National Cancer Institute grant CA098364. JLA and BDH were supported by National Heart Lung 
and Blood Institute grant HL071878. This study was made possible through the Genetic Analysis Workshops that are supported by $\mathrm{NIH}$ grant R0I GM03I575 from the National Institute of General Medical Sciences.

This article has been published as part of BMC Proceedings Volume 3 Supplement 7, 2009: Genetic Analysis Workshop 16. The full contents of the supplement are available online at http://www.biomedcentral.com/ $\underline{1753-656 \mid / 3 \text { ? issue }=\text { S7. }}$.

\section{References}

I. Gotto AM Jr: Management of dyslipidemia. Am J Med 2002, I 12:IOS-18S.

2. Gotto AM Jr: High-density lipoprotein cholesterol and triglycerides as therapeutic targets for preventing and treating coronary artery disease. Am Heart J 2002, I44: S33-S42.

3. Diabetes Genetics Initiative of Broad Institute of Harvard and MIT, Lund University, Novartis Institutes of BioMedical Research, Saxena R, Voight BF, Lyssenko V, Burtt NP, de Bakker PI, Chen H, Roix JJ, Kathiresan S, Hirschhorn JN, Daly MJ, Hughes TE, Groop L, Altshuler D, Almgren P, Florez JC, Meyer J, Ardlie K, Bengtsson Boström K, Isomaa B, Lettre G, Lindblad U, Lyon HN, Melander O, Newton-Cheh C, Nilsson P, Orho-Melander M, Råstam L, Speliotes EK, Taskinen MR, Tuomi T, Guiducci C, Berglund A, Carlson J, Gianniny L, Hackett R, Hall L, Holmkvist J, Laurila E, Sjögren M, Sterner M, Surti A, Svensson M, Svensson M, Tewhey R, Blumenstiel B, Parkin M, Defelice M, Barry R, Brodeur W, Camarata J, Chia N, Fava M, Gibbons J, Handsaker B, Healy C, Nguyen K, Gates C, Sougnez C, Gage D, Nizzari M, Gabriel SB, Chirn GW, Ma Q, Parikh H, Richardson D, Ricke D and Purcell S: Genome-wide association analysis identifies loci for type $\mathbf{2}$ diabetes and triglyceride levels. Science 2007, 3 | 6:|33|-|336.

4. Kathiresan S, Manning AK, Demissie S, D'Agostino RB, Surti A, Guiducci C, Gianniny L, Burtt NP, Melander O, Orho-Melander M, Arnett DK, Peloso GM, Ordovas JM and Cupples LA: A genomewide association study for blood lipid phenotypes in the Framingham Heart Study. BMC Med Genet 2007, 8(Suppl I): SI7-S26.

5. Kathiresan S, Melander O, Guiducci C, Surti A, Burtt NP, Rieder MJ, Cooper GM, Roos C, Voight BF, Havulinna AS, Wahlstrand B, Hedner T, Corella D, Tai ES, Ordovas JM, Berglund G, Vartiainen E, Jousilahti P, Hedblad B, Taskinen MR, Newton-Cheh C, Salomaa V, Peltonen L, Groop L, Altshuler DM and Orho-Melander M: Six new loci associated with blood low-density lipoprotein cholesterol, high-density lipoprotein cholesterol or triglycerides in humans. Nat Genet 2008, 40:189-197.

6. Kathiresan S, Melander O, Anevski D, Guiducci C, Burtt NP, Roos C, Hirschhorn JN, Berglund G, Hedblad B, Groop L, Altshuler DM, Newton-Cheh $C$ and Orho-Melander $M$ : Polymorphisms associated with cholesterol and risk of cardiovascular events. N Engl J Med 2008, 358:1240-1249.

7. Horne BD, Anderson JL, Carlquist JF, Muhlestein JB, Renlund DG, Bair TL, Pearson RR and Camp NJ: Generating genetic risk scores from intermediate phenotypes for use in association studies of clinically significant endpoints. Ann Hum Genet 2005, 69: 176-186.

8. Purcell S, Neale B, Todd-Brown K, Thomas L, Ferreira MA, Bender D, Maller J, Sklar P, de Bakker PI, Daly MJ and Sham PC: PLINK: a tool set for whole-genome association and population-based linkage analyses. Am J Hum Genet 2007, 81:559-575.

9. Abo R, Knight S, Wong J, Cox A and Camp NJ: hapConstructor: automatic construction and testing of haplotypes in a Monte Carlo framework. Bioinformatics 2008, 24:2105-2017.

10. SPSS Inc: SPSS for Windows (v. 15.0.0.). Chicago; SPSS Inc.; 2006.

II. Kathiresan S, Willer C], Peloso GM, Demissie S, Musunuru K, Schadt EE, Kaplan L, Bennett D, Li Y, Tanaka T, Voight BF, Bonnycastle LL, Jackson AU, Crawford G, Surti A, Guiducci C, Burtt NP, Parish S, Clarke R, Zelenika D, Kubalanza KA, Morken MA Scott LJ, Stringham HM, Galan P, Swift AJ, Kuusisto J, Bergman RN, Sundvall J, Laakso M, Ferrucci L, Scheet P, Sanna S, Uda M, Yang O, Lunetta KL, Dupuis J, de Bakker PI, O'Donnell CJ, Chambers JC, Kooner JS, Hercberg S, Meneton P, Lakatta EG, Scuteri A, Schlessinger D, Tuomilehto J, Collins FS, Groop L, Altshuler D, Collins R, Lathrop GM, Melander O, Salomaa V, Peltonen L, OrhoMelander M, Ordovas JM, Boehnke M, Abecasis GR, Mohlke KL and
Cupples LA: Common variants at 30 loci contribute to polygenic dyslipidemia. Nat Genet 2009, 4I:56-65.

12. Cohen JC, Kiss RS, Pertsemlidis A, Marcel YL, McPherson R and Hobbs HH: Multiple rare alleles contribute to low plasma levels of HDL cholesterol. Science 2004, 305:869-872

13. Meigs JB, Shrader P, Sullivan LM, McAteer JB, Fox CS, Dupuis J Manning AK, Florez JC, Wilson PW, D'Agostino RB Sr and Cupples LA: Genotype score in addition to common risk factors for prediction of type 2 diabetes. N Engl J Med 2008, 359:2208-2219.

14. Knight S, Abo RP, Wong J, Thomas A and Camp NJ: Pedigree association: assigning individual weights to pedigree members for genetic association analysis. BMC Proc 2009, 3(suppl 7):SI2I.
Publish with Bio Med Central and every scientist can read your work free of charge

"BioMed Central will be the most significant development for disseminating the results of biomedical research in our lifetime. "

Sir Paul Nurse, Cancer Research UK

Your research papers will be:

- available free of charge to the entire biomedical community

- peer reviewed and published immediately upon acceptance

- cited in PubMed and archived on PubMed Central

- yours - you keep the copyright
BioMedcentral 